\title{
Acute Single-Stage Reconstruction of Multiligament Knee Injuries Using the Ligament Advanced Reinforcement System
}

\author{
Jie Tao ${ }^{\text {a }}$ Xia Li $^{\mathrm{a}}$ Zihui Zhou ${ }^{\mathrm{a}}$ Zhenan Zhu ${ }^{\mathrm{b}}$ \\ a Department of Orthopedics, Shanghai First People's Hospital and bepartment of Orthopedics, Shanghai Ninth \\ People's Hospital, School of Medicine, Shanghai Jiao Tong University, Shanghai, China
}

\author{
Key Words \\ Multiligament Injuries · Knee · Dislocation · Ligament \\ advanced reinforcement system $\cdot$ Reconstruction . \\ Cruciate and collateral ligaments
}

\begin{abstract}
Objective: The purpose of the study was to report our early outcome in the management of multiligament knee injuries with the ligament advanced reinforcement system (LARS). Subjects and Methods: Between 2007 and 2010, 9 of 11 patients operated on for multiligament knee injuries were included in this study; 2 patients were excluded due to complicated neurovascular injuries, open knee dislocations and severe comorbidities. All patients were managed acutely ( $<3$ weeks) by reconstructions of the cruciate and collateral ligaments with LARS ligament and were followed up for an average of 30 months (18-46 months). Results: The mean Lysholm score of the 9 patients at final follow-up was around 90 (range 88-94) with an average Tegner activity score of 5.5. The postoperative function of 1 case of KD11 and 2 cases of KD-111 was rated as 'A,' while the remaining cases were rated ' $B$ '. At final follow-up, minor osteoarthritic degeneration was detected in 1 case of KD-III and 2 cases of KD-IV. Superficial infection developed in 1 case,
\end{abstract}

\begin{tabular}{ll}
\hline KARGER & $\begin{array}{l}\text { ( } 2013 \text { S. Karger AG, Basel } \\
1011-7571 / 13 / 0224-0373 \$ 38.00 / 0 \quad \text { Karger }\end{array}$ \\
E-Mail karger@karger.com & $\begin{array}{l}\text { This is an Open Access article licensed under the terms of the } \\
\text { www.karger.com/mpp }\end{array}$ \\
& $\begin{array}{l}\text { Creative Commons Attribution-NonCommercial 3.0 Un- } \\
\text { ported license (CC BY-NC) (www.karger.com/OA-license), } \\
\text { applicable to the online version of the article only. Distribu- } \\
\text { tion permitted for non-commercial purposes only. }\end{array}$
\end{tabular}

and no cases of knee synovitis and premature osteoarthritis were recorded. Conclusion: A creditable outcome at mean of 30 months' follow-up was obtained in acute single-stage reconstruction of uncomplicated multiligament knee injuries with LARS ligament.

Copyright $\odot 2013$ S. Karger AG, Basel

\section{Introduction}

Knee dislocation is a rare and intriguing injury, which commonly involves partial or even complete disruption of the soft tissue integrity of femorotibial articulation. First described by Sir Astley Cooper in 1825 [1], knee dislocation is known for its rare incidence of less than $0.2 \%$ [2] of all orthopedic scenarios and stunning amputation rates. However, despite the fact that modern arthroscopyassisted reconstruction of disrupted ligaments has now become the standard of care [3], the most effective treatment for traumatic dislocation of the knee remains controversial due to the gravity of injuries and difficulties of evidence-based case pooling. Stiffness attributed to prolonged mandatory immobilization after neurovascular reanastomosis, a staged reconstructive protocol and unaggressive rehabilitation was still an unsolved problem 
Table 1. Injury details of the 9 patients with traumatic knee dislocation

\begin{tabular}{|c|c|c|c|c|c|c|c|c|c|}
\hline Case & $\begin{array}{l}\text { Age } \\
\text { years }\end{array}$ & Gender & $\begin{array}{l}\text { Mechanism } \\
\text { of injury }\end{array}$ & $\begin{array}{l}\text { Side } \\
\text { of injury }\end{array}$ & Injury pattern & Associated injuries & $\begin{array}{l}\text { Intra-articular } \\
\text { pathology }\end{array}$ & $\begin{array}{l}\text { Time interval } \\
\text { before definitive } \\
\text { treatment, days }\end{array}$ & $\begin{array}{l}\text { Follow-up } \\
\text { interval } \\
\text { months }\end{array}$ \\
\hline 2 & 46 & M & MVA & $\mathrm{R}$ & $\mathrm{ACL}+\mathrm{PCL}+\mathrm{MCL}+\mathrm{LCL}$ & \multirow{3}{*}{$\begin{array}{l}\text { blunt abdominal trauma } \\
\text { multiple rib fractures }\end{array}$} & $\mathrm{M}+\mathrm{L}$ meniscus & 17 & 46 \\
\hline 3 & 40 & $\mathrm{~F}$ & MVA & $\mathrm{R}$ & $\mathrm{ACL}+\mathrm{PCL}+\mathrm{LCL}$ & & L meniscus & 20 & 18 \\
\hline 4 & 28 & M & sport & $\mathrm{R}$ & $\mathrm{ACL}+\mathrm{PCL}+\mathrm{MCL}+\mathrm{LCL}$ & & $\mathrm{M}+\mathrm{L}$ meniscus & 10 & 36 \\
\hline 7 & 29 & $\mathrm{~F}$ & sport & $\mathrm{L}$ & PCL+LCL+PLC & \multirow{2}{*}{ humeral fractures } & L meniscus & 7 & 38 \\
\hline 8 & 21 & M & sport & $\mathrm{L}$ & $\mathrm{PCL}+\mathrm{LCL}+\mathrm{PLC}$ & & & 8 & 26 \\
\hline 9 & 35 & M & MVA & $\mathrm{R}$ & $\mathrm{ACL}+\mathrm{PCL}+\mathrm{LCL}$ & blunt abdominal trauma & & 15 & 24 \\
\hline
\end{tabular}

MVA = Motor vehicle accident; $\mathrm{M} / \mathrm{L}$ meniscus = medial/lateral meniscus

which precluded patients from returning to preinjury levels of work and daily activities. 'Benign knee dislocation', described by Wascher et al. [4], features isolated knee injury with mild or no neurovascular compromise and intact bony structures. Thus, Wascher et al. [4] pointed out that uncomplicated patients managed by single-stage reconstructive protocol and followed by early and aggressive rehabilitation achieved good clinical outcome.

In the clinical scenario of multiple knee ligament injuries, the source of autologous grafting material is in scarcity. Allografts were effective alternatives without donor site morbidity. However, they might require prolonged avoidance of sport activities up to 12 months during revascularization [5], which failed the patients in need of a vigorous postoperative rehabilitation protocol to attain a better functional recovery. Under this unique circumstance, advanced synthetic ligaments such as LARS could play a bigger role, which has led to a better KOOS score in terms of early return to sports and recreational activities in a prospective, randomized study [6]. Encouraged by good early results, a protocol was established in our institute for LARS application in functionally demanding adult patients with benign knee dislocation. The purpose of this study was to evaluate the clinical results of this protocol, in which contemporary surgical techniques were employed.

\section{Subjects and Methods}

Between 2007 and 2010, 11 patients with benign knee dislocations (i.e. no neurovascular compromise and intact bony structures) presented to our trauma institute. Urgent joint reduction was conducted under general anesthesia, and meanwhile the neurovas- cular status of the affected limb was carefully examined before and after reduction. We currently use computed tomography angiograms for any patients with asymmetrical peripheral pulses or an ankle-brachial index $<0.9$ [7]. Patients were then placed in hinged knee braces after successful reduction, or in spanning external fixators for any remaining subluxation on lateral radiographs after reduction [8]. Examinations under anesthesia supplemented by a magnetic resonance imaging protocol were adopted to delineate injury patterns according to the classification of Schenck [9].

Two cases were excluded due to neurovascular insufficiencies necessitating procedures of reanastomosis and a prolonged period of immobilization. Hence, 9 patients were included and managed acutely ( $<3$ weeks) by reconstructions of the cruciate ligaments and repair or augmentation of medial and/or lateral structures with LARS ligament (Surgical Implants and Devices, Arc-surTille, France). Of the 9 patients (male: 6; female: 3 ), the median age was 32 years (range 19-46 years). There were $2 \mathrm{KD}-1,1 \mathrm{KD}-\mathrm{II}, 4$ $\mathrm{KD}-\mathrm{III}$ and $2 \mathrm{KD}-\mathrm{IV}$ injuries according to Schenck classification. The details of the injuries are summarized in table 1 . All patients were regularly followed up for an average of 30 months (range 18-46) at intervals of 2 months.

\section{Diagnostic Arthroscopy}

Reconstructive procedures were commonly delayed for 7-21 days after injury to allow capsular structures to heal and to minimize fluid extravasation during arthroscopy. During this period the knee was mobilized with continuous passive motion.

Routine arthroscopy with low fluid pressure was performed with an extremely low threshold for conversion to open surgery, in case of extravasation. Meniscal, cartilage and cruciate injuries were documented, with repair or meniscoplasty performed subsequently. To facilitate exposure and preparation of the tibial posterior cruciate ligament (PCL) insertion, a posteromedial working portal was often established under direct visualization using an inside-out technique. In contrast to total debridement of cruciate footprints, anterior cruciate ligament (ACL) and PCL stumps (about $1 \mathrm{~cm}$ ) were retained, which anchored to the meshwork of the LARS to maximize in-growth of the original tissue, thus preserving some vascular and proprioceptive nerve supply [10]. 
Table 2. ROM and knee joint laxity tests of the 9 patients at final follow-up visit

\begin{tabular}{llllllllll}
\hline Case & Injury pattern & ROM $\left({ }^{\circ}\right)$ & Lachman & Valgus & Varus & $\begin{array}{l}\text { Posterior } \\
\text { drawer }\end{array}$ & $\begin{array}{c}\text { Dial test } \\
\text { Pivot shift }\end{array}$ & $\begin{array}{l}\text { Reversed } \\
\text { pivot shift }\end{array}$ \\
\hline 1 & ACL+PCL+MCL & $0-125$ & negative & + & negative & negative & negative & negative & negative \\
2 & ACL+PCL+MCL+LCL & $0-92$ & negative & negative & negative & negative & + & negative & negative \\
3 & ACL+PCL+LCL & $0-135$ & negative & negative & + & + & negative & negative & negative \\
4 & ACL+PCL+MCL+LCL & $1-88$ & + & negative & negative & negative & + & negative \\
5 & ACL+PCL & $0-130$ & negative & negative & negative & negative & negative & negative & negative \\
6 & PCL+MCL & $0-125$ & negative & + & negative & + & negative & negative & negative \\
7 & PCL+LCL+PLC & $1-128$ & negative & negative & + & negative & + & negative & negative \\
8 & ACL+PCL+LCL & $0-120$ & negative & negative & negative & negative & + & negative & negative \\
9 & ACL+PCL+LCL & $2-125$ & negative & negative & negative & + & negative & negative & negative \\
\hline
\end{tabular}

Tunnel Preparation and Femoral Fixation

The tunnel preparations for PCL and ACL reconstructions with LARS ligament were undertaken following previously described techniques $[3,11]$.

For extreme cases of traumatic total knee dislocation, rebuild of the popliteal tendon as a static structure was mandatory. An acute repair or augmentation of the posterolateral corner was preferred, especially for the patients with Kennedy type IV knee dislocation.

A modified LaPrade et al. [12] PLC surgical technique was used. Briefly, LARS 60- or 80-gauge fibers were used, depending on the weight of the patients. The diameter of the drill hole was 6 $\mathrm{mm}$ for the tibial and femoral tunnels in all patients. The artificial implants were first fixed by interference-fit titanium screws with diameters of $8 \mathrm{~mm}$ at the femoral site. The tunnel of the popliteal tendon rested more medially and closer to the proximal tibiofibular joint than that of the lateral collateral ligament (LCL).

Medial collateral ligament (MCL) injuries were managed through an incision centered over the medial epicondyle using LARS.

\section{Graft Fixation}

In combined ACL and PCL reconstructions, the PCL graft was first tightened and fixed to the tibia by interference screws with knee flexion at $90^{\circ}$ and in neutral rotation in order to reestablish the central pivot of the knee [13]. The ACL was then fixed with an interference screw into the tibial tunnel with the knee in $20-30^{\circ}$ of flexion. With the combination of ACL, PCL, MCL, LCL and posterolateral injuries, the author preferred to stabilize the PCL first, followed by the MCL; then LCL tensioning was done due to collateral displacement of femorotibial articulation, and finally the posterolateral corner was tensioned and also fixed at $30^{\circ} \mathrm{knee} \mathrm{flex-}$ ion before tibial fixation of the ACL graft [14]. In addition, adequate reduction and intact hardware were further confirmed by intraoperative radiography.

\section{Postoperative Management}

Epidural anesthesia was left in place for 2-3 days to improve tolerance for range of motion (ROM) exercises. To prevent heterotopic ossification, indomethacin ( $25 \mathrm{mg}$ thrice daily for 3 weeks) was prescribed. The limb was initially locked in full extension within a hinged brace. Exercises immediately following surgery included passive knee extension to neutral and isometric quadriceps sets with the knee in full extension. Patients were allowed flexion to $60^{\circ}$ within 1 week, increasing progressively to over $90^{\circ}$ by the 4 th postoperative week with the affected knee in a hinged brace against posterior tibial subluxation. Active-assisted ROM exercises were initiated after 2 weeks if tolerated. Patients were allowed begin weight-bearing mobilization after 6 weeks, progressing to full weight-bearing by 3 months. Bracing was commonly discontinued at 12 weeks.

\section{Assessment}

A detailed objective and subjective assessment of all patients was conducted by an independent observer, including ROM measurement with goniometer, instrumented Lachman and posterior drawer tests at $80^{\circ}$ using the Rolimeter (Aircast, Summit, N.J., USA), the 'dial test' for posterolateral instability and the pivot and reverse pivot tests $[15,16]$, and these were compared to the uninjured limb. Laxity was categorized as negative,,+++ , or +++ , and the presence or absence of an endpoint was recorded. Knee function was assessed using the International Knee Documentation Committee (IKDC2000) chart [17] and the Lysholm score [18]. Physical activity levels were measured using the Tegner Activity Scale [19] at intervals of 3 months. Finally, the Kellgren and Lawrence [20] classification system of osteoarthritis was used for the evaluation of radiographic arthritis.

\section{Results}

Instrumented ROM averaged $0.5-106^{\circ}$ with minor restriction of extension of $1-2^{\circ}$ in 3 cases. Two KD-IV cases achieved flexion of near $90^{\circ}$ without extension loss. The knee laxity clinical tests are given in table 2 . Only case 1 with unaugmented MCL was rated + laxity. Minor laxity in the dial test was recorded in 4 of 6 cases with combined PCL and LCL or PLC injuries.

The average Lysholm score (table 3) at final follow-up was around 90 (range 88-94) with an average Tegner activity score of 5.5. Postoperative function of 1 case of $\mathrm{KD}$ II and 2 cases of KD-III was rated as 'A', normal, i.e. al- 
Table 3. Knee functional scores of the 9 patients at final follow-up visit

\begin{tabular}{|c|c|c|c|c|c|c|c|}
\hline 1 & 34 & $\mathrm{M}$ & $\mathrm{ACL}+\mathrm{PCL}+\mathrm{MCL}$ & $\mathrm{ACL}+\mathrm{PCL}$ reconstruction & 94 & 6 & A \\
\hline 2 & 46 & $\mathrm{M}$ & $\mathrm{ACL}+\mathrm{PCL}+\mathrm{MCL}+\mathrm{LCL}$ & $\begin{array}{l}\text { ACL+PCL reconstruction } \\
\text { MCL+LCL augmentation }\end{array}$ & 89 & 5 & B \\
\hline 3 & 40 & $\mathrm{~F}$ & $\mathrm{ACL}+\mathrm{PCL}+\mathrm{LCL}$ & $\mathrm{ACL}+\mathrm{PCL}$ reconstruction & 90 & 5 & $\mathrm{~B}$ \\
\hline 4 & 28 & $\mathrm{M}$ & $\begin{array}{l}\mathrm{ACL}+\mathrm{PCL} \\
\mathrm{MCL}+\mathrm{LCL}\end{array}$ & $\begin{array}{l}\text { ACL+PCL reconstruction } \\
\text { MCL+LCL augmentation }\end{array}$ & 86 & 5 & B \\
\hline 6 & 37 & $\mathrm{~F}$ & PCL+MCL & $\begin{array}{l}\text { PCL reconstruction } \\
\text { MCL augmentation }\end{array}$ & 91 & 6 & $\mathrm{~B}$ \\
\hline 7 & 29 & $\mathrm{~F}$ & $\mathrm{PCL}+\mathrm{LCL}+\mathrm{PLC}$ & $\begin{array}{l}\text { PCL reconstruction } \\
\text { LCL+PLC augmentation }\end{array}$ & 92 & 6 & A \\
\hline 8 & 21 & $\mathrm{M}$ & $\mathrm{ACL}+\mathrm{PCL}+\mathrm{LCL}$ & $\begin{array}{l}\text { ACL+PCL reconstruction } \\
\text { LCL augmentation }\end{array}$ & 90 & 5 & B \\
\hline
\end{tabular}

Table 4. Kellgren and Lawrence grading of radiographic assessment

\begin{tabular}{lll}
\hline Case & Injury Pattern & Grading (0-4) \\
\hline 1 & ACL+PCL+MCL & 0 \\
2 & ACL+PCL+MCL+LCL & 1 \\
3 & ACL+PCL+LCL & 0 \\
4 & ACL+PCL+MCL+LCL & 1 \\
5 & ACL+PCL & 0 \\
6 & PCL+MCL & 0 \\
7 & PCL+LCL+PLC & 0 \\
8 & ACL+PCL+LCL & 0 \\
9 & ACL+PCL+LCL & 1 \\
\hline
\end{tabular}

most restored to their preinjury level of activities, while the remaining cases were rated 'B', near normal, i.e. return to work with mild modifications.

At the final follow-up visit, the Kellgren and Lawrence [20] grading of radiographic assessment detected minor osteoarthritic degeneration in $1 \mathrm{KD}$-III and $2 \mathrm{KD}$-IV cases (table 4). The patients complained of occasional knee pain, which could be controlled with oral nonsteroid anti-inflammatory drugs.

There was no sign of compartment syndrome and deep venous thrombosis detected perioperatively. Case 4 developed superficial infection in the lateral incision and was successfully managed with dedicated wound care. There were no cases of arthrofibrosis and ligament loosening. According to Kellgren and Lawrence [20] grading of follow-up radiography, no cases of premature osteoarthritis correlated with intra-articular synovitis were recorded.

\section{Discussion}

LARS, as an evolved synthetic ligament device with strong biomechanical properties, has recently gained popularity [21-23]. Better and consistent results in sports-and-recreation scores have been documented in a LARS group as early as 2 months postoperatively compared to a BPTB group in ACL reconstruction [24]. In the clinical scenario of multiple knee ligament injuries, the source of autologous grafting material is in scarcity. Allografts were effective alternatives without donor site morbidity. However, they might have required prolonged avoidance of activities up to 12 months during revascularization [25], which precluded the patients in need of a vigorous postoperative rehabilitation protocol to attain a better functional recovery. Under the unique circumstance of multiligament knee injuries, advanced synthetic ligaments such as LARS could play a bigger role.

Ranger et al. [26] reported the largest case series of multiligament knee injuries treated acutely with LARS. Our Lysholm and Tegner activity scores were better, with 90 vs. 78.5 and 5.5 vs. 5 , respectively, while ROM was still comparable with almost no extension loss. In terms of complications, we did not have cases of perioperative compartment syndrome and arthrofibrosis, but 14/71 cases needed revision of arthrolysis. The confounded inclusion of high and low energy cases and the technique of open reconstruction in the series of Ranger et al. [26] might clarify the differences in outcome between their study and ours, although the distribution of injury pattern according to Schenck classification was similar. Rel- 
Fig. 1. a The figure shows the image of case 2 after injury. The patient, a 46-year-old male, got a severe injury during a motor vehicle accident, which was classified as IKD-IV. b After close reduction under general anesthesia, anteroposterior radiographs confirmed only partial reduction. The limb was temporarily placed in a plaster splint before external fixator application.

Fig. 2. a The plain anteroposterior lateral radiographs after 6 months of operation showed that his right knee was anatomically reduced with all disrupted ligaments (ACL+PCL+MCL+LCL+PLC) reconstructed with LARS ligaments. b The plain lateral radiographs showed that his right knee was anatomically reduced 6 months after all 5 ligament reconstructions.
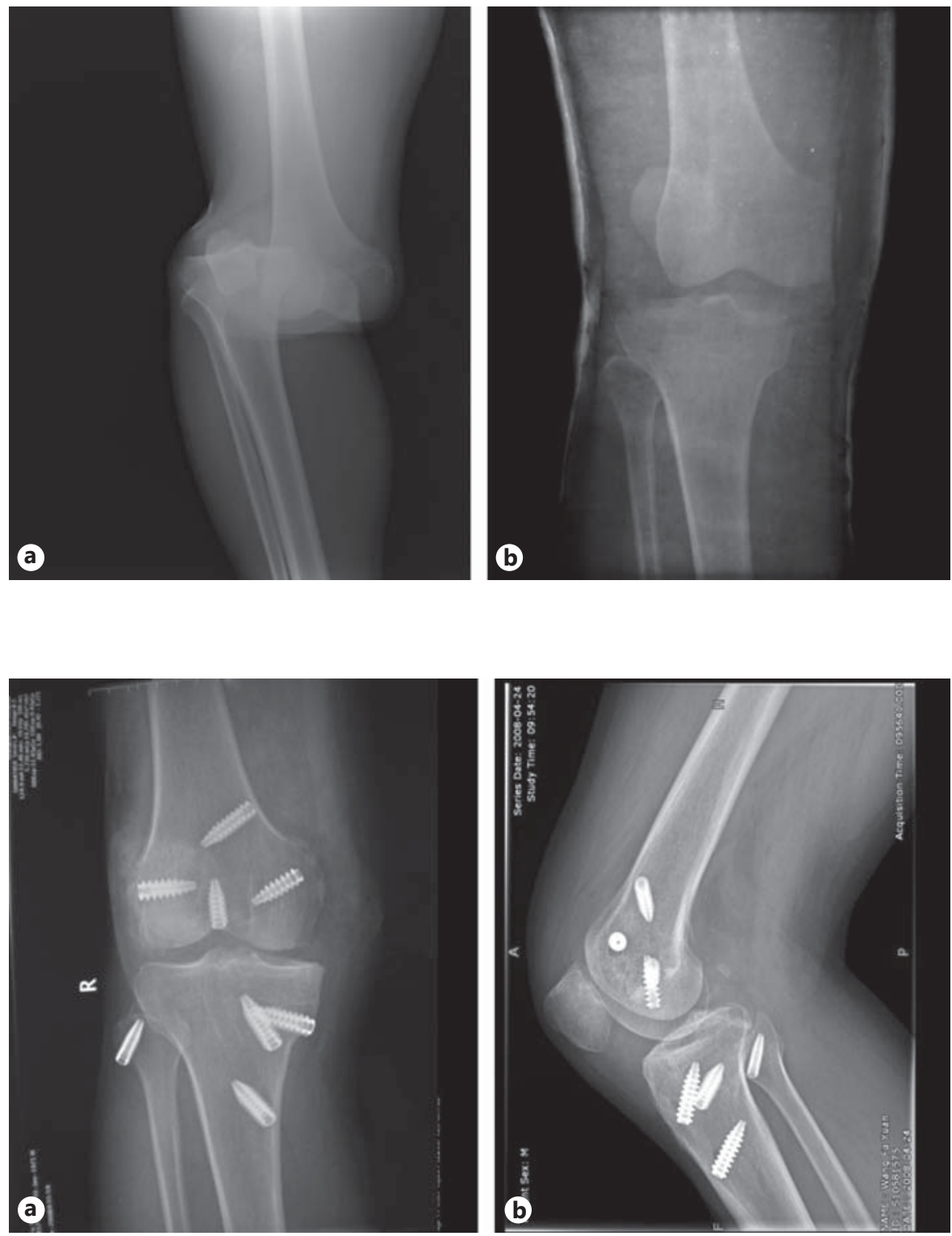

atively benign injuries, less duration of tourniquet application and surgery, low fluid pressure arthroscopy and early CPM rehabilitation may all contribute to alleviate the rate of complications.

A viable stump of ligaments is thought to be important as it allows new ligamentous and neurovascular tissue to regenerate along the synthetic scaffold [27]. It has previously been suggested that the LARS might not be appropriate without a quality bicruciate stump [28]. We reconstructed all disrupted structures acutely with bicruciate viable stumps preserved intact, which might improve the integration of LARS artificial ligaments to attain a stable knee joint. It could be confirmed that our patients only got minor residual laxity in clinical testing through the follow-up period as long as 46 months.

In the study, case 2 (46-year-old male patient) got a right knee dislocation (fig. 1a) due to a motor vehicle accident. After close reduction under general anesthesia, the knee was temporarily placed in a plaster splint (fig. 1b). Six months postoperatively, the radiographs (fig. 2a, b) showed normal femorotibial articulation was restored with LARS ligaments in place. Full weight-bearing was unrestricted after the operation, and the patient could even manage walking with a load of $100 \mathrm{~kg} 4$ months after surgery. After 46 months of follow-up, the patient had a stable and functional knee, even as a physical laborer. 
According to Pospula and Abu Noor [29], women were more frequently affected by periprosthetic fractures of the knee joint. As in our series, LARS ligaments were fixed with metal interference screws through multiple bone tunnels, which might increase the risk of periprosthetic fractures through aggressive postoperative protocol. We only adopted single-bundle ACL and PCL reconstruction, in case of possible conflicts of bone tunnels, which would compromise the integrity of the bone-metal-ligament construct. Hence, no cases of screw loosening and fractures were observed in our study.

Our study also has inherent limitations, such as retrospective design, small case series and a relatively short follow-up period. Therefore, future research should focus more on long-term outcome, ideally over a period of 5 years or longer. Meanwhile, research related to the safety and cost-effectiveness of LARS ligament is still highly expected.

\section{Conclusion}

Acute single-stage reconstruction of uncomplicated multiligament knee injuries with LARS ligament has a creditable outcome at mean of 30 months' follow-up. Along with auto- and allocounterparts, LARS could readily serve as a graft of choice in the reconstruction scenario of multiligament knee injuries.

\section{References}

$>1$ Sir Cooper A: A treatise on dislocations and on fractures of the joints: fractures of the neck of the thigh-bone. 1823. Clin Orthop Relat Res 2007;458:6-7.

-2 Robertson A, Nutton RW, Keating JF: Dislocation of the knee. J Bone Joint Surg Br 2006; 88:706-711.

$\checkmark 3$ Chhabra A, Cha PS, Rihn JA, Cole B, Bennett $\mathrm{CH}$, Waltrip RL, Harner CD: Surgical management of knee dislocations. Surgical technique. J Bone Joint Surg Am 2005;87(suppl 1):1-21.

$\checkmark 4$ Wascher DC, Becker JR, Dexter JG, Blevins FT: Reconstruction of the anterior and posterior cruciate ligaments after knee dislocation. Results using fresh-frozen nonirradiated allografts. Am J Sports Med 1999;27:189-196.

$\checkmark 5$ Andersson D, Samuelsson K, Karlsson J: Treatment of anterior cruciate ligament injuries with special reference to surgical technique and rehabilitation: an assessment of randomized controlled trials. Arthroscopy 2009;25:653-685.

$\checkmark 6$ Nau T, Lavoie P, Duval N: A new generation of artificial ligaments in reconstruction of the anterior cruciate ligament. Two-year followup of a randomised trial. J Bone Joint Surg Br 2002;84:356-360.

7 Hollis JD, Daley BJ: 10-year review of knee dislocations: is arteriography always necessary? J Trauma 2005;59:672-675, discussion pp 675-676.

$>8$ Seroyer ST, Musahl V, Harner CD: Management of the acute knee dislocation: the Pittsburgh experience. Injury 2008;39:710-718.

$>9$ Schenck R Jr: Classification of knee dislocations: Oper Tech Sports Med 2003;11:193198.

10 Taft TN, Almekinders LC: The Dislocated Knee. Knee Surgery. Baltimore, Williams \& Wilkins, 1994, pp 837-857.
1 Lavoie P, Fletcher J, Duval N: Patient satisfaction needs as related to knee stability and objective findings after ACL reconstruction using the LARS artificial ligament. Knee 2000;7: 157-163.

12 LaPrade RF, Spiridonov SI, Coobs BR, Ruckert PR, Griffith CJ: Fibular collateral ligament anatomical reconstructions: a prospective outcomes study. Am J Sports Med 2010;38:20052011.

13 Hughston JC, Barrett GR: Acute anteromedial rotatory instability. Long-term results of surgical repair. J Bone Joint Surg Am 1983;65: 145-153.

14 Fanelli GC: Treatment of combined anterior cruciate ligament-posterior cruciate ligamentlateral side injuries of the knee. Clin Sports Med 2000;19:493-502.

15 Balasch H, Schiller M, Friebel H, Hoffmann F: Evaluation of anterior knee joint instability with the Rolimeter. A test in comparison with manual assessment and measuring with the KT-1000 arthrometer. Knee Surg Sports Traumatol Arthrosc 1999;7:204-208.

16 Ganko A, Engebretsen L, Ozer H: The rolimeter: a new arthrometer compared with the KT-1000. Knee Surg Sports Traumatol Arthrosc 2000;8:36-39.

17 International Knee Documentation Committee: Knee ligament injury and reconstruction evaluation; in Aichroth PM, Cannon WD Jr (eds): Knee Surgery: Current Practice. London, Martin Dunitz, 1992, pp 759-760.

18 Lysholm J, Gillquist J: Evaluation of knee ligament surgery results with special emphasis on use of a scoring scale. Am J Sports Med 1982; 10:150-154.

19 Tegner Y, Lysholm J: Rating systems in the evaluation of knee ligament injuries. Clin Orthop Relat Res 1985;198:43-49.

20 Kellgren JH, Lawrence JS: Radiological assessment of osteo-arthrosis. Ann Rheum Dis 1957;16:494-502.
21 Li B, Wen Y, Wu H, et al: Arthroscopic singlebundle posterior cruciate ligament reconstruction: retrospective review of hamstring tendon graft versus LARS artificial ligament. Int Orthop 2009;33:991-996.

22 Shen G, Xu Y, Dong Q, et al: Arthroscopic posterior cruciate ligament reconstruction using LARS artificial ligament: a retrospective study. J Surg Res 2012;173:75-82.

23 Gao K, Chen S, Wang L, et al: Anterior cruciate ligament reconstruction with LARS artificial ligament: a multicenter study with 3- to 5-year follow-up. Arthroscopy 2010;26:515-523.

24 Nau T, Lavoie P, Duval N: A new generation of artificial ligaments in reconstruction of the anterior cruciate ligament. Two-year followup of a randomised trial. J Bone Joint Surg Br 2002;84:356-360.

25 Andersson D, Samuelsson K, Karlsson J: Treatment of anterior cruciate ligament injuries with special reference to surgical technique and rehabilitation: an assessment of randomized controlled trials. Arthroscopy 2009;25:653-685.

26 Ranger P, Renaud A, Phan P, Dahan P, De Oliveira E Jr, Delisle J: Evaluation of reconstructive surgery using artificial ligaments in 71 acute knee dislocations. Int Orthop 2011; 35:1477-1482.

27 Huang JM, Wang Q, Shen F, Wang ZM, Kang YF: Cruciate ligament reconstruction using LARS artificial ligament under arthroscopy: 81 cases report. Chin Med J (Engl) 2010;123: 160-164.

28 Dericks G Jr: Ligament advanced reinforcement system anterior cruciate ligament reconstruction. Op Tech Sports Med 1995;3: 187-205.

29 Pospula W, Abu Noor T: Periprosthetic fractures of the femur after hip and knee replacement. Analysis of treatment results in Al Razi Hospital. Med Princ Pract 2009;18:198-203. 